\title{
Large carnivore habitat suitability modelling for Romania and associated predictions for protected areas
}

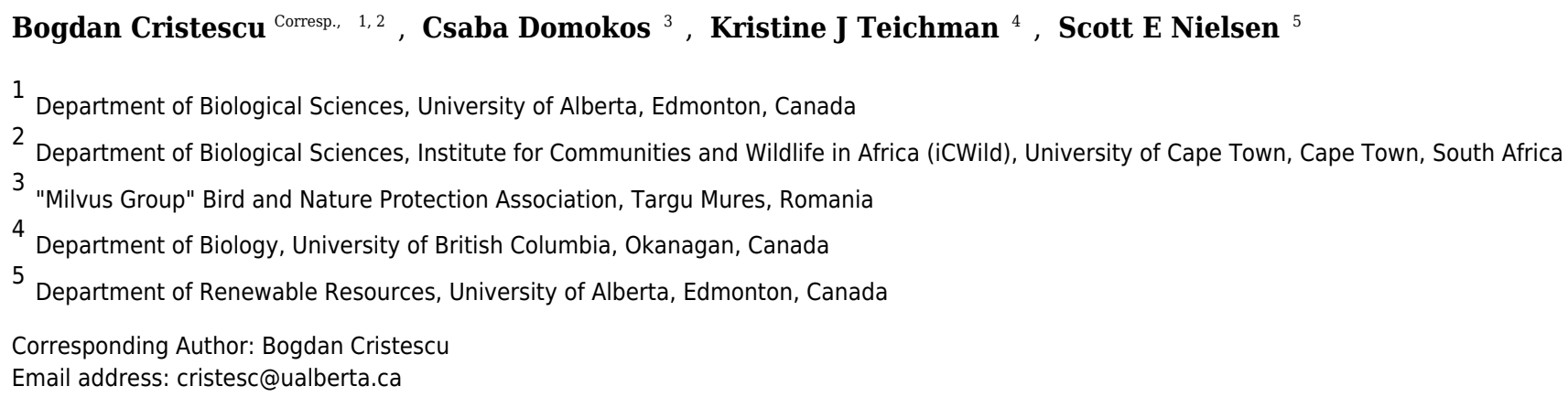

Habitat characteristics associated with species occurrences represent important baseline information for wildlife management and conservation, but have rarely been assessed for countries recently joining the EU. We used footprint tracking data and landscape characteristics in Romania to investigate the occurrence of brown bear (Ursus arctos), gray wolf (Canis lupus) and Eurasian lynx (Lynx lynx) and to compare model predictions between Natura 2000 and national-level protected areas (gap analysis). Wolves were more likely to occur where rugged terrain was present. Increasing proportion of forest was positively associated with occurrence of all large carnivores, but forest type (broadleaf, mixed, or conifer) generally varied with carnivore species. Areas where cultivated lands were extensive had little suitable habitat for lynx, whereas bear occurrence probability decreased with increasing proportion of built areas. Pastures were positively associated with wolf and lynx occurrence. Brown bears occurred primarily where national roads with high traffic volumes were at low density, while bears and lynx occurred at medium-high densities of communal roads that had lower traffic volumes. Based on predictions of carnivore distributions, natural areas protected in national parks were most suitable for carnivores, nature parks were less suitable, whereas EU-legislated Natura 2000 sites had the lowest probability of carnivore presence. Our spatially explicit carnivore habitat suitability predictions can be used by managers to amend borders of existing sites, delineate new protected areas, and establish corridors for ecological connectivity. To assist recovery and recolonization, management could also focus on habitat predicted to be suitable but where carnivores were not tracked. 


\section{Large carnivore habitat suitability modelling for Romania and associated}

2 predictions for protected areas

3

4 *Bogdan Cristescu ${ }^{1,2}$, Csaba Domokos ${ }^{3}$, Kristine J. Teichman ${ }^{4}$, Scott E. Nielsen ${ }^{5}$

$7 \quad{ }^{1}$ Department of Biological Sciences, University of Alberta, Edmonton, Canada

9 Institute for Communities and Wildlife in Africa (iCWild), Department of Biological Sciences,

10 University of Cape Town, Cape Town, South Africa (current)

3"Milvus Group" Bird and Nature Protection Association

13 Targu Mures, Romania

${ }^{4}$ Department of Biology, University of British Columbia, Okanagan, Canada

${ }^{5}$ Department of Renewable Resources, University of Alberta, Edmonton, Canada

* Author for correspondence:

21 cristesc@ualberta.ca

24 Short title: Carnivore habitat in protected areas

25

26 


\section{ABSTRACT}

Habitat characteristics associated with species occurrences represent important baseline information for wildlife management and conservation, but have rarely been assessed for countries recently joining the EU. We used footprint tracking data and landscape characteristics in Romania to investigate the occurrence of brown bear (Ursus arctos), gray wolf (Canis lupus) and Eurasian lynx (Lynx lynx) and to compare model predictions between Natura 2000 and national-level protected areas (gap analysis). Wolves were more likely to occur where rugged terrain was present. Increasing proportion of forest was positively associated with occurrence of all large carnivores, but forest type (broadleaf, mixed, or conifer) generally varied with carnivore species. Areas where cultivated lands were extensive had little suitable habitat for lynx, whereas bear occurrence probability decreased with increasing proportion of built areas. Pastures were positively associated with wolf and lynx occurrence. Brown bears occurred primarily where national roads with high traffic volumes were at low density, while bears and lynx occurred at medium-high densities of communal roads that had lower traffic volumes. Based on predictions of carnivore distributions, natural areas protected in national parks were most suitable for carnivores, nature parks were less suitable, whereas EU-legislated Natura 2000 sites had the lowest probability of carnivore presence.

47 Our spatially explicit carnivore habitat suitability predictions can be used by managers to amend 48 borders of existing sites, delineate new protected areas, and establish corridors for ecological connectivity. To assist recovery and recolonization, management could also focus on habitat predicted to be suitable but where carnivores were not tracked. 


\section{INTRODUCTION}

55

56

57 58

Long-term persistence of many large carnivore species relies on the existence of vast natural areas of core protected habitat that act as sources for the surrounding landscape (Noss et al., 1996; Soule \& Terborgh, 1999). Identifying patterns of carnivore occurrence in relation to the distribution of natural habitats and human land use can be used to inform protected area designation (Carroll et al., 2001) or management (Reed \& Merenlender, 2008). In Europe, carnivore habitat suitability has been quantified in Scandinavia (e.g., May et al., 2008) and central European countries (e.g., Kobler \& Adamic, 2000; Huck et al., 2010). However, uncertainties over habitat suitability for species of European Community interest (e.g., large carnivores) remain prevalent in countries that have only recently joined the European Union (EU).

Many large carnivores have been extirpated from their historic habitats in Europe (Enserink \& Vogel, 2006; Dalerum et al., 2009). However, carnivore decline has not been uniform and while some populations have been eradicated, others have survived and even expanded or increased (Linnell et al., 2001; Chapron et al., 2014). Currently population statuses of large carnivores vary widely among EU member states. While the brown bear (Ursus arctos Linnaeus), gray wolf(Canis lupus Linnaeus) and Eurasian lynx (Lynx lynx Linnaeus) are now making a come-back in the EU, Romania (which joined the EU in 2007) has historically housed large and stable populations of these species (Boitani, 2000; Breitenmoser et al., 2000; Swenson et al., 2000; Van Maanen et al., 2006).

Brown bears, wolves and lynx are protected in Romania by national and EU legislation, as well as international Conventions. Carnivore habitat in Romania is protected in EU-legislated Natura 2000 sites, national parks (IUCN category II) and nature parks (IUCN category V). Because Natura 2000 sites were designated based on expert opinion, accurate spatial information (e.g., GIS) 
77 and, to a lesser degree, by incorporating previous ecological modeling outputs, Natura 2000 sites

78 might have higher habitat value for carnivores than national-level protected areas (national parks

79 and nature parks). Historical decisions to designate national parks and nature parks mostly

80 revolved around areas with little anticipated economic potential (such as rugged mountainous

81 regions), and/or were spearheaded by scientists with interests in specific habitats or ecological

82 communities. This latter approach to protected area designation has been common practice

83 worldwide (Scott et al., 2001; Joppa \& Pfaff, 2009). Investigating differences in habitat suitability

84 across protected area types could help strategize the channeling of limited conservation resources

85 to protected areas that host the best carnivore habitat. In addition, comparing carnivore occurrence

86 from confirmed distribution records and habitat suitability analyses could help identify

87 management needs for protected areas of certain types, thereby improving protection effectiveness.

88 In Romania carnivore research at the country-wide extent has focused on assessing

89 distribution patterns from raw footprint tracking data (with outputs such as supplementary Figs.

90 S1-S3) with little consideration of underlying habitat characteristics. Yet, carnivore habitat might

91 exist outside the current extent of carnivore distribution, and habitat delineation could assist

92 recovery efforts and range expansion. Only two quantitative studies have investigated potential

93 habitat for brown bear, gray wolf and Eurasian lynx in Romania. Salvatori (2004) applied a

94 Mahalanobis distance to identify environmental suitability for carnivores in the Carpathian

95 Mountains using carnivore observation records, environmental variables and expert opinion. Van

96 Maanen et al. (2006) used Marxan software to identify a network of potential protected areas for

97 Romania, under the assumption that forest, grassland and shrub represent prime habitat for

98 carnivores. Subsequently to these studies, a reassessment of the occurrence of EU-listed species in

99 Romanian protected areas was recommended (Iojă et al., 2010). 
101 procedure, while also contrasting candidate models in an information theoretic approach, we 1)

102 identify habitat characteristics associated with the occurrence of the three large carnivore species

103 present in Romania and 2) assess whether the Natura 2000 network supersedes the national (pre-

104 Natura 2000) protected area network in relation to carnivore habitat suitability, by inspecting the

105 predicted values of carnivore occurrence obtained at 1). Our objectives are therefore to

106 quantitatively select a set of habitat suitability predictors that are meaningful for the carnivore

107 occurrence dataset; and evaluate which protected area types in the current protected area system

108 have the highest probability of carnivore presence.

109

110 MATERIALS \& METHODS

111 Study Area

112 The study encompassed the extent of Romania. The country has varied topography,

113 including the Carpathian Mountains, hills, plateaus and plains. Elevations range from below sea

114 level to $2,544 \mathrm{~m}$. Predominant natural land cover is forest, composed of broadleaf, mixed

115 broadleaf-conifer and conifer forest. Dominant broadleaf tree species include oak (Quercus spp.),

116 European beech (Fagus sylvatica), European hornbeam (Carpinus betulus), common ash

117 (Fraxinus excelsior) and silver birch (Betula pendula), whereas dominant conifer tree species

118 include silver fir (Abies alba), Norway spruce (Picea abies), European larch (Larix decidua) and

119 Scots pine (Pinus sylvestris). Small amounts of shrub habitat occur throughout the country, most

120 commonly in the transitional areas between forest and grassland or forest and agricultural land, as

121 well as in abandoned agricultural areas. Moors and heathlands occur above tree line whereas

122 natural grasslands occur at the highest elevations and in the lower elevation plains region. Human 
123 population is at moderate densities compared to other European countries, with mean density of

12486.1 inhabitants $/ \mathrm{km}^{2}$ in 2015

125 (http://ec.europa.eu/eurostat/tgm/table.do?tab=table\&init=1\&language=en\&pcode=tps00003\&pl

126 ugin=1), although most areas outside urban centers have relatively low human densities.

128 Carnivore Information

129 During spring of each year, the Romanian Ministry of Environment, Waters and Forest 130 coordinates a country-wide large carnivore survey across all 2,148 Wildlife Management Units

131 (WMUs). The mean $\pm \mathrm{SD}$ size of a WMU is $109.7 \pm 31.9 \mathrm{~km}^{2}\left(\right.$ range $\left.=25.7-341.8 \mathrm{~km}^{2}\right)$. The

132 survey involves hiking designated transects to inventory carnivore footprints encountered along

133 the transects within each WMU. At the time the survey is carried out, most brown bears including

134 females with cubs have already emerged from winter dens, whereas wolves and Eurasian lynx are

135 active throughout the year. The survey protocol requires recording of date and time of tracking,

136 with landmark locations recorded along the track (Fundatia Carpati \& ICAS, 2011). Transect

137 length, as well as name of river basin, are also noted. Lengths and widths of carnivore footprints

138 encountered are recorded in a standardized form and photographs of the footprints are taken with

139 a ruler or tape measure for reference. Tracking data are centralized at the county level and later

140 converted to densities for each WMU (animals per $100 \mathrm{~km}^{2}$ ), based on raw number of tracks

141 recorded, filtered by footprint lengths and widths to try to minimize counting the same animal

142 more than once.

143 Although the stated purpose is to inventory individual carnivores within each WMU, the

144 methodology does not produce an absolute population census because some carnivores likely 145 move between neighboring WMUs thereby leading to double-counting. Although surveys are 
146 planned in a synchronized manner over a short period across the entire country, this is not

147 achievable for all WMUs because of different tracking conditions and because larger WMU sizes

148 sometimes require longer sampling periods. In addition, detectability issues also would preclude

149 an absolute census of carnivores in each WMU. These various factors likely affect density

150 calculations and we are in agreement with Popescu et al. (2016), who also expressed concerns

151 regarding the robustness of density estimates derived as described above. For our analyses we

152 chose to convert density estimates to coarser scale data, i.e. carnivore occurrence (1/0) per WMU,

153 by setting all density estimates $>0$ as " 1 ", and all density estimates $=0$ as " 0 ". We used carnivore

154 data collected in the year 2011 in the country-wide carnivore survey, which is the most recent

155 dataset available to the public. Data were digitized from published carnivore distribution-density

156 hardcopy maps compiled by the Romanian Forest Research and Management Institute (Jurj \&

157 Ionescu, 2011; supplementary Figs. S1-S3).

158

159 Spatial Environmental Predictors

160 We used a suite of polygon and polyline vector GIS layers and a $30 \mathrm{~m}$ resolution digital

161 elevation model (DEM) to generate raster grids for use in statistical modelling (Table 1). The

162 starting spatial resolution (grain) of grid cells for GIS analyses was $1 \mathrm{~km} \times 1 \mathrm{~km}$. This resolution

163 is adequate for regional level spatial modelling for large carnivore species (Rodriguez \& Delibes,

164 2004; Treves et al., 2004; Teichman et al., 2013). To obtain raster grids relevant to carnivore home

165 range level, for all predictor variables we calculated focal statistic mean values in GIS within

166 rectangular moving windows that had areas specific to the study species: $8 \mathrm{~km} \times 8 \mathrm{~km}$ window for

167 brown bears (home range $=65 \mathrm{~km}^{2}$ ), $11 \mathrm{~km} \times 11 \mathrm{~km}$ window for both gray wolves (home range $=$

$168128.5 \mathrm{~km}^{2}$ ) and Eurasian lynx (home range $=129 \mathrm{~km}^{2}$ ). Home range sizes were based on telemetry 
169 studies of large carnivores in Romania with the average home range size used for adult bears,

170 wolves and lynx (Promberger, 2001; 2002; 2003). We then used the moving window outputs to

171 estimate mean values of rasters within all Romanian WMUs, which were available in polygon

172 format.

173

174 Habitat (Natural)

175 Abiotic

176 We obtained a Digital Elevation Model (DEM) from the GMES RDA project (EU-DEM,

177 https:/www.eea.europa.eu/). We resampled the DEM from $30 \mathrm{~m} \times 30 \mathrm{~m}$ to $1 \mathrm{~km} \times 1 \mathrm{~km}$ and

178 estimated TRI (terrain ruggedness index) based on Riley et al.'s (1999) ruggedness model. Terrain

179 ruggedness has been shown to drive the distribution of mammalian species including carnivores

180 (Nielsen et al., 2006; May et al., 2008) largely because areas with high ruggedness have difficult

181 access for people.

182 Biotic

183

Land cover data were derived from a Corine Land Cover layer that covered the country extent (EIONET, 2013). We merged land cover categories to obtain a classification that we considered ecologically relevant (supplementary Table S1). Land cover reclassification resulted in 4 land cover types of natural habitat that included three forest classes (broadleaf, mixed, conifer) and a shrub/herbaceous class (Table 1). Poor natural habitats assumed to be of little value to carnivores composed only $1.6 \%$ of the country's land area and were excluded from these analyses. We separated forest classes in our candidate models because of increasing productivity of habitats

190 ranked from low productivity in conifer, through more productive habitats of mixed and broadleaf

191 forest. We excluded water bodies from all analyses by masking them in a GIS. 
192 Habitat (Human)

193 Reclassification of the original Corine Land Cover layer that covered the country extent

194 (EIONET, 2013) resulted in 3 land cover types representative of human-modified habitat, that

195 included cultivation (plant crops and orchards), pasture (livestock grazing areas) and artificial

196 (human infrastructure). We included a cultivation land cover variable primarily because bears

197 might be attracted to cultivated lands and orchards to forage on plant foods (Domokos C., 198 unpublished data). We used pasture as an individual land cover class because of a hypothesized

199 association between carnivore and ungulate distributions, given that many European wild 200 ungulates use pastures in spring (Linnell \& Andersen, 1995; Godvik et al., 2009). We used an 201 artificial land cover variable because we expected human-built areas to be avoided by carnivores 202 (e.g., Niedziałkowska et al., 2006).

203 We exported the linear vector layer of the Romanian road network from the 204 OpenStreetMap (OSM) project database (http://www.openstreetmap.org/, Open Database License $205[\mathrm{ODbl}] \mathrm{v} 1.0)$. We generated 3 road layers from the original layer, each containing one road 206 category in decreasing order of traffic levels: national, county and communal roads (the latter 207 include small roads used primarily by villagers, as well as forestry roads). A large body of literature 208 shows that roads can impose major influences on carnivore occurrence (Forman \& Alexander, 209 1998; Trombulak \& Frissel, 2000; Coffin, 2007), but animals often respond differently to major 210 roads compared to smaller ones (Mace et al., 1996; Northrup et al., 2012). Roads can have direct 211 negative effects through vehicular collisions (Huber et al., 1998; Kaczensky et al., 2003), or

212 indirect effects that can result in habitat fragmentation (Graves et al., 2006), altered behavior 213 (McLellan \& Shackleton, 1988) and increased stress levels (Kerley et al., 2002). 


\section{Statistical Analyses and Predictions for Protected Areas}

216 Habitat suitability models

217 We used logistic regression ( $\mathrm{R}$ function $\mathrm{glm}$ ) to estimate presence/absence $(1 / 0)$ of

218 carnivores across Romania, where presence/absence was derived from footprint data at the WMU

219 level. All predictor variables were standardized before including in the modelling procedure, by

220 subtracting their means and dividing by standard deviations ( $\mathrm{R}$ code attached). To account for

221 potential autocorrelation, for all models we computed Driscoll and Kraay (1998) standard errors

222 that are robust to cross-sectional autocorrelation. Calculation of these standard errors (R package

223 sandwich) involved setting a lag length as proposed by Hoechle (2007) based on Newey and West

224 (1994). The Driscoll and Kraay (1998) sandwich estimator was applied after logistic regression,

225 so parameter estimates from modelling were those from conventional logistic regression. Results

226 are reported as odds ratios, which are obtained by exponentiating the parameter estimate $(\beta)$ of a

227 given predictor. For a one unit increase in the respective predictor, odds ratios $>1$ indicate an

228 increase and odds ratios $<1$ a decrease in the odds of carnivore occurrence.

229 We formulated candidate models a priori to reflect competing hypotheses on determinants

230 of carnivore occurrence, which expanded our hypothesis 1) (stating that predictors of carnivore

231 occurrence will include both habitat and human variables, particularly forest and roads). We

232 delineated 20 competing hypotheses, grouped in 5 model sub-sets (supplementary Tables S2-S4).

233 Carnivore occurrence at the country-level was hypothesized to be potentially best explained by

234 Natural habitat characteristics that included abiotic, biotic, or abiotic \& biotic variables,

235 specifically terrain morphology and natural land cover types (Model set 1); Human-generated

236 habitat features, with variables including land cover types created by humans and roads (Model

237 set 2); Natural (abiotic) and Human-generated predictors (Model set 3); Natural (biotic) and 
238 Human-generated variables (Model set 4); and Natural (abiotic \& biotic) and Human-generated

239 variable combinations (Model set 5). The same variable combinations were used in occurrence

240 models for each carnivore species, for a total of 3 sets of candidate models (supplementary Tables

241 S2-S4; variable justification: Table 1).

242 Highly correlated variables $(r>|0.6|)$ were not included in the same model structure.

243 Predictor variables for carnivore occurrence were included in their linear as well as squared

244 (quadratic) form when ecologically relevant. For example, we expected carnivores to avoid areas

245 with low terrain ruggedness because these would presumably be more likely to be used by people,

246 select areas of intermediate ruggedness for habitat security, and avoid areas of high ruggedness

247 because such areas incur high energetic cost of movement and might have lower ecosystem

248 productivity (Table 1).

249 We ranked models using Akaike's Information Criterion (AIC) and $\triangle$ AIC (Burnham \&

250 Anderson, 2002). For each carnivore species we compared the residual deviance of the top model

251 with the deviance of the corresponding null model and calculated the percent deviance explained

252 as a measure of model fit. Variance inflation factors (VIFs) were calculated to identify potential

253 collinearity in the top models for each species, as collinearity can influence model reliability. Top

254 models were not affected by collinearity issues except between variables that were included in the

255 same model structure in their linear and squared forms, which are expected to be collinear without

256 affecting the reliability of regression parameter estimates. We plotted predicted probabilities for

257 the top model for each carnivore to help interpretation of squared terms (R package ggplot2) and

258 mapped the predicted values at the WMU scale.

259 We used $K$-fold cross validation (Boyce et al., 2002) to estimate predictive accuracy of the

260 most supported occurrence models for each species (R package boot). This model validation 
261 technique entails withholding a portion of the occurrence data for model testing, which occurs

262 after the model is trained with multiple partitions of the original data. $K$-fold cross validation is

263 suited for situations when independent datasets are not available for model validation (Boyce et

264 al., 2002). We applied Huberty's heuristic rule for deciding the model training to testing ratio

265 (Huberty, 1994) for each species. Based on number of predictor variables in top models, we used

266 ratios of $80 \%$ model training to $20 \%$ testing for all carnivores.

267

268 Habitat in protected areas

269 For each carnivore species and protected area type (national park, nature park, Natura

270 2000), we calculated the proportion of protected areas of a given type that intersected WMUs

271 which had confirmed presence of the respective carnivore based on raw footprint data. This

272 allowed us to explore which protected area types had proportionally more confirmed carnivore

273 presence records in the overlapping WMUs. Polygon layers for national and nature parks were

274 obtained from the Romanian Ministry of Environment, Waters and Forest

275 (http://www.mmediu.ro/beta/domenii/protectia-naturii-2/arii-naturale-protejate/). To obtain a

276 layer for Natura 2000 sites, we clipped to the extent of Romania the Natura 2000 protected areas

277 polygon layer (v.2012), which we obtained from the European Environment Agency

278 (https://www.eea.europa.eu/data-and-maps/data/natura-4/natura-2000-spatial-data/natura-2000-

279 shapefile-1). Because some Natura 2000 sites were small in extent, we imposed minimum area

280 thresholds based on the home range sizes used in focal statistical analyses (brown bears, $65 \mathrm{~km}^{2}$;

281 gray wolf, $128.5 \mathrm{~km}^{2}$; Eurasian lynx, $129 \mathrm{~km}^{2}$ ). The rationale was that even if some small sites

282 might have suitable habitat, the spatial extent of a site has to accommodate at least one home range

283 of a large carnivore in order for the site to be suited for carnivore conservation. 
285 habitat suitability values (relative probabilities of occurrence) from occurrence models across the

2863 protected area types. These predicted values were extracted in GIS as $1 \mathrm{~km} \times 1 \mathrm{~km}$ pixel values

287 that were then averaged across all protected areas of a given type, based on spatial extents of 288 polygon layers delineating protected areas of the respective type. Mean predicted values were 289 contrasted between the 3 types of protected areas, with larger means being indicative of better 290 habitat. Standard deviations were also calculated to inspect the spread of habitat suitability values

291 between sites of a given protected area type. No statistical testing was necessary as the data 292 represented a complete inventory of pixels in the study area extent.

293 GIS procedures were performed in ArcGIS v.10.0 (ESRI, USA), Q-GIS v.2.14.1 (Open

294 Source Geospatial Foundation Project, USA) and Geospatial Modelling Environment v.0.7.2.0

295 (Beyer, 2013). Statistical procedures were carried out in R Studio Version 1.0.143 (RStudio Team, 296 2016).

297

298

\section{RESULTS}

Brown bear habitat was predicted to occur primarily in the Central, Central-Western and

300 Northern parts of Romania (Fig. 1). These regions coincide roughly with the Carpathian Mountains

301 chain and their foothills. Gray wolf habitat was also predicted in these areas, but was more widely

302 distributed throughout the country (Fig. 2). Predicted habitat for Eurasian lynx was located in the 303 same broad geographic areas as bear habitat (Fig. 3).

304

305 Brown Bear

306 Habitat suitability models 
308 (Table 2) and had substantial power of prediction (mean cross-validation estimate of accuracy

309 0.934). For 1 unit increase in proportion of mixed forest cover or proportion of conifer forest

310 cover, the odds of bears occurring increased by $127 \%$ (Table 3 ). Bear occurrence appeared to have

311 non-linear association with areas with crops and orchards, but the confidence intervals for the

312 linear term overlapped zero. For 1 unit increase in proportion of built area, the odds of bear

313 occurrence decreased by $35 \%$ and the probabilities of bears occurring at increasing artificial land

314 cover approached and reached zero (Fig. 4). An increase in density of national roads by 1 unit

315 resulted in $58 \%$ decrease in odds of bear presence at alpha level 0.90 . The relationship between

316 communal road densities and bear occurrence was overall a positive association, but strongly non-

317 linear. The relative probability of bear presence was close to zero at communal road densities less

318 than $0.3 \mathrm{~km} / \mathrm{km}^{2}$, had a steep increase between road densities $0.3-0.65 \mathrm{~km} / \mathrm{km}^{2}$ and still increased

319 at densities of $0.65-0.8 \mathrm{~km} / \mathrm{km}^{2}$, but at lower slope of the fitted curve (Fig. 4).

320

$321 \quad$ Habitat in protected areas

322 Based on raw presence data from fooprint tracking, bears occurred proportionately most

323 often in national parks (87\%), less often in nature parks (71\%) and least frequently in Natura 2000

324 areas $(50 \%)$. Based on predicted mean relative probability of occurrence values, habitat suitability

325 for bears was on average high in national parks, lower in nature parks, and lowest in Natura 2000

326 sites (Fig. 5). However, there was substantial variability in habitat suitability both between and

327 within protected area types. For example, when considering protected area types with the lowest

328 and highest mean occurrence probabilities, some Natura 2000 sites had higher suitability than the

329 mean suitability recorded for national parks. 


\section{Gray Wolf}

331 Habitat suitability models

332 The most supported gray wolf occurrence model explained $>62 \%$ of the deviance (Table

333 2) and had substantial predictive power (mean cross-validation estimate of accuracy 0.925 ). Wolf

334 occurrence had a strong positive and non-linear association with rugged terrain (Table 3).

335 Occurrence probability increased sharply between ruggedness values of 10 - 40 and plateaued at 336 maximum probability level when ruggedness surpassed 60 (Fig. 4). A 1 unit increase in proportion 337 of area covered by broadleaf forest had an associated increase of 39\% in odds of wolf presence.

338 Conifer forest increase by 1 unit yielded a 30-fold (2926\%) increase in odds of wolf occurrence.

339 In addition, for 1 unit linear increase in pasture, the odds of wolf presence also increased by $66 \%$

340 at alpha level 0.90.

341

342 Habitat in protected areas

343 The raw presence data from fooprint tracking showed that proportionally wolves were

344 present primarily in national parks $(87 \%)$, followed by nature parks $(71 \%)$ and Natura 2000 sites

345 (52\%). Mean habitat suitability for gray wolf was also greatest for national parks, followed by

346 nature parks and Natura 2000 sites (Fig. 5). However, similar to bears, habitat suitability for wolves

347 varied greatly between and within protected area types, with some Natura 2000 sites having better 348 habitat conditions than the mean suitability of national parks.

350 Eurasian Lynx

351 Habitat suitability models 

excellent predictive power (mean cross-validation estimate of accuracy 0.951 ). For 1 unit increase

354 in proportion of mixed forest cover, the odds of lynx occurrence increased by $177 \%$ (Table 3 ). As

355 proportion of crops and orchards increased by 1 unit, the odds of lynx presence decreased by $84 \%$.

356 Areas with pastures had a positive non-linear association with lynx occurrence. The probability of

357 lynx occurrence increased at a steeper slope of the fit curve when proportion pasture was higher 358 than 0.20 , than when pasture was at lower values (Fig. 4). Density of communal roads was also 359 positively non-linearly associated with lynx occurrence, with low occurrence probability at roads 360 densities of $0-0.25 \mathrm{~km} / \mathrm{km}^{2}$, sharply increasing odds at densities of $0.25-0.50 \mathrm{~km} / \mathrm{km}^{2}$, and 361 maximum odds at densities greater than $0.50 \mathrm{~km} / \mathrm{km}^{2}$.

362

363 Habitat in protected areas

364 Similar to the other carnivores, lynx raw presence data suggested that lynx were 365 proportionately mostly present in national parks $(87 \%)$, followed by nature parks $(71 \%)$ and 366 Natura 2000 sites (42\%). Mean probabilities of occurrence were also high for national parks, lower 367 for nature parks and lowest for Natura 2000 areas (Fig. 5). As was the case for bear and wolf, 368 habitat suitability for lynx varied between and within protected area types, with some Natura 2000 369 sites having better lynx habitat than the mean suitability of national parks.

370

\section{DISCUSSION}

372 Statistical habitat models of carnivore occurrence (presence/absence) enabled us to 373 evaluate and predict country-wide landscape responses of carnivores in Romania and habitat 374 suitability of protected areas. The occurrences of brown bear and Eurasian lynx were best predicted 
375 by models with identical structure (Model set 4, H16) that included variables for Natural (biotic)

376 and Human-generated habitat characteristics. The occurrence of gray wolf was best predicted by

377 a model with variables denoting Natural (abiotic \& biotic) and Human-generated features (Model

378 set 5, H20). Our interpretations below regarding the associations between predictor variables and

379 the response variable are based on top models, which explained most of the variation in the variable

380 of interest (presence or absence of carnivore). This is important to emphasize because for a given

381 predictor variable, the observed strength of its relationship with the response variable is modulated

382 by the other predictors in the model. Basing our interpretations on outcomes of best models as

383 identified via ranking a candidate model set, instead of on a singular global model, provided a

384 strong foundation for inferences on carnivore habitat suitability.

385 Terrain ruggedness occurred in the best wolf habitat model, but not in the top bear and lynx

386 models. Wolves showed strong selection for rugged areas, similar to wolves in Scandinavia (May

387 et al., 2008). We highlight the fact that the scale of the analysis was carnivore home range level,

388 and therefore our interpretations are home range level inferences. For example, while rugged

389 terrain was an important predictor of wolf occurrence, this does not imply that wolves move

390 through extremely rugged terrain, but that ruggedness is an important home range component for

391 their persistence, possibly because it provides refuge from persecution. Throughout much of their

392 range, wolves are one of the most highly persecuted carnivore, including in areas with legal

393 protection (Liberg et al., 2012). Although evidence is limited, in Romania wolf persecution is

394 probably widespread and has been one of the drivers for implementing applied research and

395 conservation programs with wolf-human conflict mitigation components (Carpathian Large

396 Carnivore Project, WOLFLIFE "Implementing best practices for the in-situ conservation of the

397 species Canis lupus in the Eastern Carpathians"). 

increased probability of occurrence for all 3 carnivores. However, not all forest types were

400 included in top models. Conifer forest was the only forest type that occurred in top models for all

4013 carnivores, but confidence intervals overlapped zero for lynx. Brown bears can exploit vegetative

402 foods such as berries in conifer forests even the spring following autumn berry ripening (Cristescu

403 B., unpublished data), and they also select conifer forest for bedding (Cristescu et al., 2013). Red 404 deer (Cervus elaphus) have a high proportion of conifers in their winter diets (Gebert \& 405 Verheyden-Tixier, 2008) and this might explain the association of wolves with conifer forests at 406 this time of the year, given that red deer are a major prey for wolves in European ecosystems 407 (Okarma, 1995). The use of mixed forests by bear and lynx has been previously documented 408 (Große et al., 2003; Boutros et al., 2007) and is likely associated with food distribution, such as 409 winter-killed ungulate carcasses (Green et al., 1997) or berries from previous autumn for bears; 410 and roe deer (Capreolus capreolus) for lynx, given that roe deer are Eurasian lynx's main prey 411 (Jędrzejewski et al., 1993). The wolf's association with broadleaf forest might indicate that wolves 412 are able to exploit ungulates which are known to use broadleaf forest in spring (Bongi et al., 2008).

413 Occurrence of lynx in areas with low proportion of cultivated land could be because human

414 land use could displace lynx outside the cultivation season. It is unknown whether lynx in Romania 415 show seasonal variability in occurrence on agricultural lands, or avoid these altogether. Brown 416 bears sometimes use these areas during the timing of agricultural production (Domokos C., 417 unpublished data), which would explain the slight association of bears with cultivated areas we 418 found, although modelled probabilities of bear presence in these areas were low. Wolves and lynx occurred in areas with high proportion of pastures, a pattern possibly 420 associated with ungulate use of pastures for feeding (Putman, 1986; Godvik et al., 2009). The year- 
421 round use of pastures by wolves has been previously reported (Meriggi et al., 1991). Habitat edges

422 at the forest-pasture interface were not captured in our modelling but probably present good 423 opportunities for carnivores to hunt ungulates (Podgórski et al., 2008). In Romania, bears also use

424 pastures for foraging but at different times of the year than the timing of footprint surveys in the 425 snow (Roellig et al., 2014).

As expected, probabilities of occurrence in relation to artificial (built) areas were low for 427 all carnivores especially bears, for which confidence intervals for the artificial parameter estimate did not overlap zero. Built areas generally provide little natural forage, although in some areas they may provide human-originated foods that can attract carnivore and result in human-wildlife conflict situations (Cristescu et al., 2016). Regions with high proportion of built-up areas could also have low carnivore occurrence because of human-mediated carnivore removal, or because carnivores avoid these unsafe areas.

Avoidance of high national road density by brown bears is possibly indicative of an adverse response to vehicular traffic and comparable to grizzly bear avoidance of areas with major roads and traffic in Canada (Gibeau et al., 2002). In North America it is generally accepted that road 436 development is unfavorable to grizzly bear conservation (Nielsen et al., 2006). Confidence interval overlap with zero for national road density in wolf and lynx occurrence models suggests a weaker response of these species to traffic at the current road density. This is in contrast with the avoidance of high road density by wolves in Poland (Jedrzejewski et al., 2005) and with extensive road networks impeding lynx movement in Germany (Kramer-Schadt et al., 2004). We caution that the

441 ongoing and projected increase in the density and quality of transport infrastructure in Romania 442 might surpass within-home range road tolerance thresholds for these species. Occurrence of brown 443 bear and lynx in areas with medium or high communal road density, and lack of influence of 
444 communal roads on wolf occurrence, suggest that the first two species might be less responsive to

445 human traffic on these small roads than wolf. Alternatively, lack of avoidance of areas with

446 communal roads by all carnivores may be related to lower overall use of smaller roads by humans

447 in spring, when many communal roads are still covered by snow, or are inaccessible because of 448 heavy mud.

449 Based on both modelling predictions and raw footprint (presence-absence) data, the 450 national park system in Romania has higher habitat suitability for bear, wolf and lynx than EU-

451 level protected areas. In general, national parks have the strictest protective regulations and could 452 therefore, in theory, perpetuate natural habitat types free of major human intervention, or even 453 areas without human presence (e.g., core areas). Because national parks are strongholds for 454 carnivores in Romania, managers of these areas should continue to enforce strict protective 455 measures and also strive to maintain connectivity to other suitable carnivore habitat, that is ideally 456 also formally protected.

457 For all carnivore species, nature parks had lower habitat suitability value than national 458 parks, but higher mean suitability than Natura 2000 sites. However, there was substantial 459 variability in habitat suitability both between and within protected area types, which would have 460 remained undetected were we to explore carnivore occurrence from raw presence-absence data 461 only. For example, identifying specific Natura 2000 sites with better habitat than some nature or 462 national parks can assist conservation prioritization and site-level management for carnivore 463 conservation. These differential outputs between raw and modelled carnivore occurrence illustrate 464 the importance of incorporating quantitative techniques in assessments of protected area suitability 465 for large carnivores. Our results reveal that such differences are present outside protected areas 466 also (Figs. 1-3) and are possibly indicative of carnivore range restrictions from portions of suitable 
467 habitat due to human threats. Areas with suitable carnivore habitat but where carnivores were not

468 tracked should be targeted by management to assist in carnivore recovery and recolonization,

469 which are possible provided favorable management (Chapron et al., 2014).

$470 \quad$ Nature parks have fewer restrictions on human activity than national parks, with high levels

471 of tourism. Managers of nature parks could improve protected area suitability for carnivores and

472 minimize the risk of carnivore-human interactions by restricting tourism activities in the best

473 carnivore habitat. Both national and nature parks have zoning, whereas zoning is not required in

474 the case of Natura 2000 sites. An additional key difference between the three protected area

475 categories is that national parks and nature parks fall under Romanian legislation, whereas Natura

4762000 sites are under EU legislation. While we showed that habitat suitability is greatest for national

477 parks, the observed variability in habitat suitability for large carnivores in Romania is likely to

478 translate differentially into true conservation effects, with EU-level legislation operating in Natura

4792000 sites potentially acting as a protective framework against local or national interests that might

480 otherwise undermine protected area effectiveness. For example, a number of nationally protected

481 areas experience threats such as illegal logging, transport infrastructure development, mining and

482 the construction of hydroelectric power plants. In the case of Natura 2000 sites, any potential

483 conflictual cases between site authorities and other stakeholders, such as developers or

484 recreationists, can be solved at the European Commission level if possibilities offered by relevant

485 national legislation have been exhausted.

486 Because the Natura 2000 network has incorporated many of the pre-Natura 2000 protected

487 areas, for a total land base that is more extensive than the national and nature parks combined (Iojă

488 et al., 2010), the relative differences in habitat suitability between Natura 2000 sites and national

489 protected areas are likely even greater than we documented. Nonetheless, the large spatial extent 
490 of the Natura 2000 network and its EU-governed legislative framework suggest that Natura 2000

491 sites have potential to play a significant role in conservation of large carnivore populations in

492 Romania and likely other European countries also. Law enforcement, environmental education of

493 local communities and viable human-wildlife conflict mitigation solutions are necessary if Natura

4942000 sites and carnivore habitat in Romania in general are to achieve higher conservation value

495 for large carnivores and species under their umbrella.

496

497 CONCLUSIONS

498 We identified a variety of habitat characteristics that are associated with carnivore 499 occurrence in Romania. Based on habitat suitability modelling, we showed that national as well as

500 EU-legislated protected areas in Romania contain suitable habitat for large carnivores, but that the

501 habitat values differ by carnivore species and according to protected area type. Quantitative

502 predictions from this work could be used for border amendments of existing sites, to delineate 503 additional protected areas, and to establish corridors for ecological connectivity (e.g., Figs. 1-3 B).

504 Even if current resources might not enable protected area expansion, the spatial outputs from

505 habitat suitability modelling can be used to focus management for safeguarding carnivores in areas

506 with high habitat suitability and confirmed carnivore presence (from footprint tracking data). The

507 results can also be used to guide the spatial prioritization of sites for implementing human-

508 carnivore conflict mitigation programs in highly suitable carnivore habitat but where carnivore

509 presence was not confirmed with footprint tracking; as well in areas with medium suitability for

510 carnivores but that can facilitate connectivity between carnivore strongholds. Law enforcement

511 and working with local communities to empower them through education and by providing tools 
512 for human-wildlife conflict mitigation can pave the way to maintaining carnivore populations,

513 carnivore re-colonization of suitable habitat, and co-existence with humans.

514

515 ACKNOWLEDGEMENTS

516 The study was part of the Milvus Group's Brown Bear Conservation and Research

517 Program. Mark Boyce facilitated initial networking. Gábor Bóné assisted with GIS layers. Peter

518 Damerell, Márton Atilla Kelemen, Tamás Papp and Tibor Sos provided comments on earlier

519 drafts. The editor (Alison Boyer), Gwen Iacona and an anonymous reviewer provided excellent

520 comments that substantially improved the manuscript.

521

522

523

524

525

526

527

528

529

530

531

532

533

534 


\section{LITERATURE CITED}

536 Beyer HL. 2013. Geospatial Modelling Environment. http://www.spatialecology.com.

537 Accessed 1 March 2015.

538 Boitani L. 2000. Action Plan for the conservation of the Wolf in Europe. Convention on

539 the Conservation of European Wildlife and Natural Habitats (Bern Convention), Nature and

540 Environment Publication No. 113, Council of Europe Publishing, Luxembourg.

541 Bongi P, Ciuti S, Grignolio S, Del Frate M, Simi S, Gandelli D, Apollonio M. 2008. Anti-

542 predator behaviour, space use and habitat selection in female roe deer during the fawning season

543 in a wolf area. Journal of Zoology 276:242-251.

544 Boutros D, Breitenmoser-Würsten C, Zimmermann F, Ryser A, Molinari-Jobin A, Capt S,

545 Güntert M, Breitenmoser U. 2007. Characterisation of Eurasian lynx Lynx lynx den sites and kitten 546 survival. Wildlife Biology 13:417-429.

547 Bouyer Y, San Martin G, Poncin P, Beudels-Jamar RC, Odden J, Linnell JDC. 2015.

548 Eurasian lynx habitat selection in human-modified landscape in Norway: Effects of different

549 human habitat modifications and behavioral states. Biological Conservation 191:291-299.

550 Boyce MS, Vernier PR, Nielsen SE, Schmiegelow FKA. 2002. Evaluating resource 551 selection functions. Ecological Modelling 157:281-300.

552 Breitenmoser U, Breitenmoser-Würsten C, Okarma H, Kaphegyi T, Kaphegyi-Wallman U, 553 Müller UM. 2000. Action Plan for the conservation of the Eurasian Lynx (Lynx lynx) in Europe.

554 Convention on the Conservation of European Wildlife and Natural Habitats (Bern Convention),

555 Nature and Environment Publication No. 112, Council of Europe Publishing, Luxembourg.

556 Burnham KP, Anderson DR. 2002. Model selection and multimodel inference. Second 557 edition. Springer-Verlag. New York, New York, USA. 
561 Carroll C, Noss RF, Paquet PC. 2001. Carnivores as focal species for conservation planning 562 in the Rocky Mountain region. Ecological Applications 11:961-980. Chapron G, Kaczensky P, Linnell JDC, von Arx M, Huber D, Andrén H, López-Bao JV,

564 Adamec M, Álvares F, Anders O, Balčiauskas L, Balys V, Bedő P, Bego F, Blanco JC, 565 Breitenmoser U, Brøseth H, Bufka L, Bunikyte R, Ciucci P, Dutsov A, Engleder T, Fuxjäger C, 566 Groff C, Holmala K, Hoxha B, Iliopoulos Y, Ionescu O, Jeremić J, Jerina K, Kluth G, Knauer F, 567 Kojola I, Kos I, Krofel M, Kubala J, Kunovac S, Kusak J, Kutal M, Liberg O, Majić A, Männil P, 568 Manz R, Marboutin E, Marucco F, Melovski D, Mersini K, Mertzanis Y, Mysłajek RW, Nowak 569 S, Odden J, Ozolins J, Palomero G, Paunović M, Persson J, Potočnik H, Quenette PY, Rauer G, 570 Reinhardt I, Rigg R, Ryser A, Salvatori V, Skrbinšek T, Stojanov A, Swenson JE, Szemethy L, 571 Trajçe A, Tsingarska-Sedefcheva E, Váňa M, Veeroja R, Wabakken P, Wölfl M, Wölfl S, 572 Zimmermann F, Zlatanova D, Boitani L. 2014. Recovery of large carnivores in Europe's modern 573 human-dominated landscapes. Science 346:1517-1519.

574 Coffin AW. 2007. From roadkill to road ecology: a review of the ecological effects of 575 roads. Journal of Transport Geography 15:396-406.

577 choice at top of the food chain. PLoS ONE 8:e82738.

578 Cristescu B, Stenhouse GB, Goski B, Boyce MS. 2016. Grizzly bear space use, survival, 579 and persistence in relation to human habitation and access. Human-Wildlife Interactions 10:240$580 \quad 257$. 
Driscoll JC, Kraay AC. 1998. Consistent covariance matrix estimation with spatially

Cover. http://sia.eionet.europa.eu/CLC2000/classes/index_html. Accessed 1 November 2014.

Review of Ecology, Evolution, and Systematics 29:207-231.

lup, ras si pisica salbatica. [In Romanian] Methodological guide for evaluating populations of bear, wolf, lynx and wildcat, Brasov.

(Cervus elaphus L.) in Europe. Mammal Review 31: 189-201. scales, trade-offs, and functional responses in red deer habitat selection. Ecology 90:699-710. 
grizzly bears in Yellowstone National Park. Journal of Wildlife Management 61:1040-1055.

606

Große C, Kaczensky P, Knauer F. 2003. Ants: A food source sought by Slovenian brown 607 bears (Ursus arctos)? Canadian Journal of Zoology 81:1996-2005.

Hoechle D. 2007. Robust standard errors for panel regressions with cross-sectional dependence. Stata Journal 7: 281-312. viewpoints. Acta Theriologica 38:385-403.

623 Habitat selection by wolves Canis lupus in the uplands and mountains of southern Poland. Acta 624 Theriologica 50:417-428. 

carnivore mari şi pisică sălbatică din România (Ursus arctos, Canis lupus, Lynx lynx şi Felis silvestris) în vederea menţinerii într-o stare favorabilă de conservare şi pentru stabilirea numărului

630 de exemplare din speciile strict protejate care se pot recolta în cadrul sezonului de vânătoare 2011631 2012". [In Romanian] Final report for "Study on estimating large carnivore and wildcat 632 populations in Romania (Ursus arctos, Canis lupus, Lynx lynx and Felis silvestris) for maintaining 633 favorable conservation status and for delineating the numbers of specimens from strictly protected 634 species which can be harvested during the 2011-2012 hunting season”. Fundatia Carpati, Institutul 635 de Cercetari si Amenajari Silvice, Universitatea "Transilvania" din Brasov. Online: 636 http://www.mmediu.ro/protectia_naturii/biodiversitate/carnivore_mari/2012-01-16/2012-01637 16_carnivore_mari_evaluare_2011_raportcarnivoremari2011.pdf.

638 Kaczensky P, Knauer F, Krze B, Jonozovic M, Adamic M, Gossow H. 2003. The impact 639 of high speed, high volume traffic axes on brown bears in Slovenia. Biological Conservation 640 111:191-204.

Kerley LL, Goodrich JM, Miquelle DG, Smirnov EN, Quigley HB, Hornocker MG. 2002. 642 Effects of roads and human disturbance on Amur tigers. Conservation Biology 16:97-108.

643 Kobler A, Adamic M. 2000. Identifying brown bear habitat by a combined GIS and 644 machine learning method. Ecological Modelling 135: 291-300.Kramer-Schadt S, Revilla E, 645 Wiegand T, Breitenmoser U. 2004. Fragmented landscapes, road mortality and patch connectivity: 646 modelling influences on the dispersal of Eurasian lynx. Journal of Applied Ecology 41:711-723.

647 Liberg O, Chapron G, Wabakken P, Pedersen HC, Hobbs NT, Sand H. 2012. Shoot, shovel 648 and shut up: cryptic poaching slows restoration of a large carnivore in Europe. Proceedings of the 649 Royal Society B 279:910-915. 
651

652

653

654

655

656

657

658

659

660

661

662 663

664

665

666

667

668

669

670

671

672

Wildlife Society Bulletin 23:31-35.

Linnell JDC, Swenson JE, Andersen R. 2001. Predators and people: conservation of large carnivores is possible at high human densities if management policy is favourable. Animal Conservation 4:345-349.

Mace RD, Waller JS, Manley TL, Lyon LJ, Zuuring H. 1996. Relationships among grizzly bears, roads and habitat in the Swan Mountains, Montana. Journal of Applied Ecology 33:13951404.

May R, Van Dijk J, Wabakken P, Swenson JE, Linnell JDC, Zimmermann B, Odden J, Pedersen HC, Andersen R, Landa A. 2008. Habitat differentiation within the large-carnivore community of Norway's multiple-use landscapes. Journal of Applied Ecology 45:1382-1391.

McLellan BN, Shackleton DM. 1988. Grizzly bears and resource-extraction industries: effects of roads on behaviour, habitat use and demography. Journal of Applied Ecology 25:451460.

Meriggi A, Rosa P, Brangi A, Matteucci C. 1991. Habitat use and diet of the wolf in northern Italy. Acta Theriologica, 36:141-151.

Newey WK, West KD. 1994. Automatic lag selection in covariance matrix estimation. The Review of Economic Studies 61:631-653.

Niedziałkowska M, Jędrzejewski W, Mysłajek RW, Nowak S, Jędrzejewska B, Schmidt K. 2006. Environmental correlates of Eurasian lynx occurrence in Poland-Large scale census and GIS mapping. Biological Conservation 133:63-69.

Nielsen SE, Stenhouse GB, Boyce MS. 2006. A habitat-based framework for grizzly bear conservation in Alberta. Biological Conservation 130:217-229. 

traffic shapes grizzly bear behaviour on a multiple-use landscape. Journal of Applied Ecology 49:1159-1167. and carnivore conservation in the Rocky Mountains. Conservation Biology 10:949-963. communities of forest ecosystems in Europe. Acta Theriologica 40:335-386.

by Eurasian lynx and its implications for species conservation. Acta Theriologica 53: 97-110.

selection functions and home-range data to identify habitat conservation priorities for brown

bears. Animal Conservation 21:352-362.

690 Promberger C. 2002. Carpathian Large Carnivore Project (CLCP): Annual report 2001. 691 Zarnesti.

692 Promberger C. 2003. Carpathian Large Carnivore Project (CLCP): Annual report 2002. 693 Zarnesti.

694 Putman RJ. 1986. Foraging by roe deer in agricultural areas and impact on arable crops. 695 Journal of Applied Ecology 23:91-99. 

area effectiveness. Conservation Letters 1:146-154.

Riley SJ, DeGloria SD, Elliot R. 1999. A terrain ruggedness index that quantifies topographic heterogeneity. Intermountain Journal of Sciences 5:23-27. lynx during a 40-year period of range contraction. Biological Conservation 118:151-161. in traditional wood-pastures in Southern Transylvania, Romania. Ursus 25:43-52. the Carpathian Mountains. Doctoral thesis, University of Southampton. 203.

712 Do they capture the full range of America's biological diversity? Ecological Applications 11:9997131007.

714 Soulé ME, Terborgh J. 1999. Conserving nature at regional and continental scales: A 715 scientific program for North America. BioScience 49:809-817.

716 Swenson J, Gerstl N, Zedrosser A, Dahle B. 2000. Action Plan for the conservation of the

717 Brown Bear (Ursus arctos) in Europe. Convention on the Conservation of European Wildlife and 
718 Natural Habitats (Bern Convention), Nature and Environment Publication No. 114. Council of

719 Europe Publishing, Luxembourg.

720 Teichman KJ, Cristescu B, Nielsen SE. 2013. Does sex matter? Temporal and spatial

721 patterns of cougar-human conflict in British Columbia. PLoS ONE 8:e74663.

722 Theuerkauf J, Jędrzejewski W, Schmidt K, Gula R. 2003. Spatiotemporal segregation of 723 wolves from humans in the Białowieża Forest (Poland). Journal of Wildlife Management 67:706724716. AP. 2004. Predicting human-carnivore conflict: a spatial model derived from 25 years of data on wolf predation on livestock. Conservation Biology 18:114-125.

Trombulak SC, Frissell CA. 2000. Review of ecological effects of roads on terrestrial and 729 aquatic communities. Conservation Biology 14:18-30.

Van Maanen E, Predoiu G, Klaver R, Soulé M, Popa M, Ionescu O, Jurj R, Negus S,

731

732 733 736 737 738 739 740
Ionescu G, Altenburg W. 2006. Safeguarding the Romanian Carpathian Ecological Network. A vision for large carnivores and biodiversity in Eastern Europe. A\&W ecological consultants, Veenwouden and ICAS Wildlife Unit, Brasov.

Zimmermann B, Nelson L, Wabakken P, Sand H, Liberg O. 2014. Behavioral responses of wolves to roads: scale-dependent ambivalence. Behavioral Ecology 25:1353-1364. 
741 Table 1. Variables considered in modelling large carnivore occurrence in Romania. Data were

742 obtained based on moving window calculations in a GIS.

743

744 Table 2. Top occurrence models for brown bear, gray wolf and Eurasian lynx. Variable codes listed 745 under "Model description" are provided in Table 1.

746

747 Table 3. Parameter estimates for top brown bear, gray wolf and Eurasian lynx occurrence models.

748 Variable codes listed under "Variable" are provided in Table 1. Estimates for which 95\%

749 confidence intervals did not overlap zero are given in bold.

750

751

752

753

754

755

756

757

758

759

760

761

762 
763 Fig. 1. A. Brown bear presence (1) and absence (0) based on footprint tracking in 2011 at the level

764 of Romania's WMUs. B. Predicted relative probabilities of brown bear occurrence based on top

765 habitat model. A. Original density data mapped in Jurj and Ionescu (2011) were digitized and

766 converted to $1 / 0$. B. Predictions refer to potential habitat, not to actual bear presence. Black ellipses

767 provide case examples of areas where conservation efforts could focus to improve habitat

768 suitability and establish/maintain ecological connectivity for brown bear.

769

770 Fig. 2. A. Gray wolf presence (1) and absence (0) based on footprint tracking in 2011 at the level

771 of Romania's WMUs. B. Predicted relative probabilities of gray wolf occurrence based on top

772 habitat model. A. Original density data mapped in Jurj and Ionescu (2011) were digitized and

773 converted to 1/0. B. Predictions refer to potential habitat, not to actual wolf presence. Black ellipses

774 provide case examples of areas where conservation efforts could focus to improve habitat

775 suitability and establish/maintain ecological connectivity for gray wolf.

776

777 Fig. 3. A. Eurasian lynx presence (1) and absence (0) based on footprint tracking in 2011 at the

778 level of Romania’s WMUs. B. Predicted relative probabilities of Eurasian lynx occurrence based

779 on our top habitat model. A. Original density data mapped in Jurj and Ionescu (2011) were

780 digitized and converted to 1/0. B. Predictions refer to potential habitat, not to actual lynx presence.

781 Black ellipses provide case examples of areas where conservation efforts could focus to improve

782 habitat suitability and establish/maintain ecological connectivity for Eurasian lynx. 783 
784 Fig. 4. Predicted relative probabilities of brown bear (A-H), gray wolf (I-P) and Eurasian lynx (Q$785 \mathrm{X}$ ) occurrence in Romania as a function of predictor variables. Relationships wherein confidence 786 intervals did not overlap zero have two asterisks (95\%) or one asterisk (90\%).

787

788 Fig. 5. Predicted mean relative probability of occurrence of large carnivores in Romanian national 789 parks (dark green bars), nature parks (medium green) and Natura 2000 sites (light green). 790 Predictions are given for A. Brown bear; B. Gray wolf; and C. Eurasian lynx. Error bars represent $791 \pm$ SD. 


\section{Table $\mathbf{1}$ (on next page)}

Variables considered in modelling large carnivore occurrence in Romania.

Data were obtained based on moving window calculations in a GIS. 


\begin{tabular}{|c|c|c|c|c|c|c|c|c|}
\hline Variable & Code & Units & $\begin{array}{l}\text { Data } \\
\text { range } \\
\text { (Bear) }\end{array}$ & $\begin{array}{l}\text { Data } \\
\text { range } \\
\text { (Wolf) }\end{array}$ & $\begin{array}{l}\text { Data } \\
\text { range } \\
\text { (Lynx) }\end{array}$ & Linearity & $\begin{array}{l}\text { Variable justification } \\
\text { (potential influence to be } \\
\text { tested in the models) }\end{array}$ & References \\
\hline \multicolumn{9}{|l|}{ Habitat (Natural) } \\
\hline \multicolumn{9}{|l|}{ Abiotic } \\
\hline $\begin{array}{l}\text { Terrain } \\
\text { ruggedness index }\end{array}$ & triXmn & $\begin{array}{l}\text { Unitless } \\
\text { (index) }\end{array}$ & $\begin{array}{l}2.61- \\
95.60\end{array}$ & $\begin{array}{l}2.61- \\
93.70\end{array}$ & $\begin{array}{l}2.61- \\
93.70\end{array}$ & $\begin{array}{l}\text { Non- } \\
\text { linear }\end{array}$ & $\begin{array}{l}\text { Carnivores might avoid flat } \\
\text { areas because these are more } \\
\text { likely to be used by people. } \\
\text { Carnivores might select } \\
\text { intermediate ruggedness for } \\
\text { habitat security, but avoid } \\
\text { high ruggedness because the } \\
\text { latter incurs high energetic } \\
\text { costs of movement and might } \\
\text { have lower ecosystem } \\
\text { productivity }\end{array}$ & $\begin{array}{l}\text { Nielsen et al., 2006; May et al., 2008; } \\
\text { Bouyer et al., } 2015\end{array}$ \\
\hline \multicolumn{9}{|l|}{ Biotic } \\
\hline Broadleaf forest & brdlfXmn & $\begin{array}{l}\text { Unitless } \\
\text { (proportion) }\end{array}$ & $0-0.99$ & $0-0.99$ & $0-0.99$ & Linear & $\begin{array}{l}\text { Broadleaf forest is selected } \\
\text { by all carnivores due to high } \\
\text { productivity for plants and } \\
\text { ungulates }\end{array}$ & $\begin{array}{l}\text { Breitenmoser et al., 2000; Bongi et al., } \\
\text { 2008; Pop et al., } 2018\end{array}$ \\
\hline Mixed forest & mixedXmn & $\begin{array}{l}\text { Unitless } \\
\text { (proportion) }\end{array}$ & $0-0.91$ & $0-0.88$ & $0-0.88$ & Linear & $\begin{array}{l}\text { Mixed forest is selected by } \\
\text { all carnivores due to high- } \\
\text { medium productivity for } \\
\text { plants and ungulates }\end{array}$ & $\begin{array}{l}\text { Meriggi et al., 1991; Breitenmoser et al., } \\
\text { 2000; Pop et al., } 2018\end{array}$ \\
\hline Conifer forest & conifXmn & Unitless & $0-0.83$ & $0-0.82$ & $0-0.82$ & Linear & $\begin{array}{l}\text { Conifer forest is weakly } \\
\text { selected by all carnivores due }\end{array}$ & $\begin{array}{l}\text { Meriggi et al., 1991; Breitenmoser et al., } \\
\text { 2000; Pop et al., } 2018\end{array}$ \\
\hline
\end{tabular}




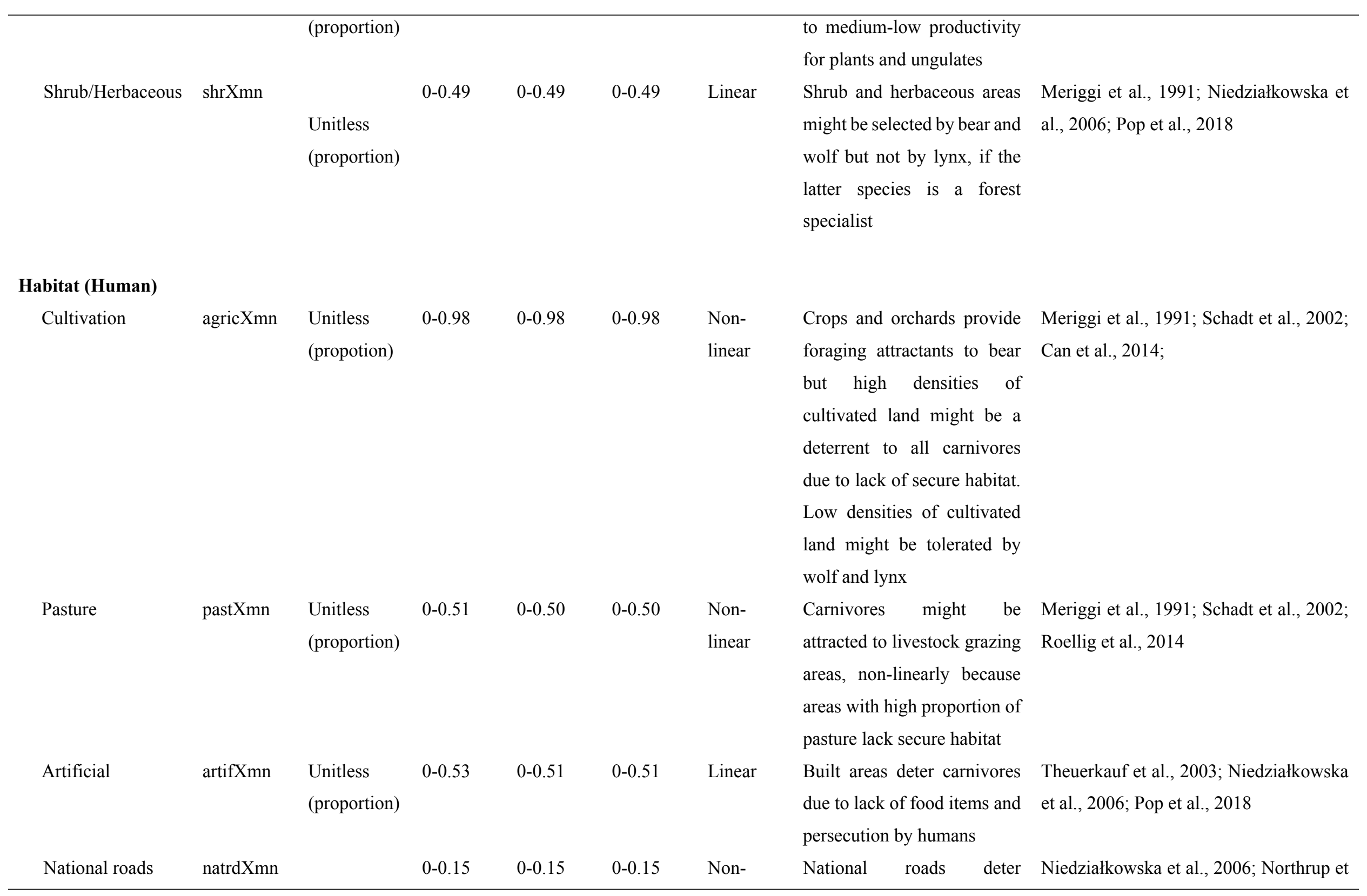




\begin{tabular}{|c|c|c|c|c|c|c|c|c|}
\hline & & $\begin{array}{l}\mathrm{km} / \mathrm{km}^{2} \\
\text { (density) }\end{array}$ & & & & linear & $\begin{array}{l}\text { carnivores due to high levels } \\
\text { of human presence/traffic. } \\
\text { Predictability of traffic could } \\
\text { result in non-linear effects } \\
\text { for some carnivores that } \\
\text { adapt to heavily roaded areas }\end{array}$ & al., 2012; Zimmermann et al., 2014 \\
\hline County roads & courdXmn & $\begin{array}{l}\mathrm{km} / \mathrm{km}^{2} \\
\text { (density) }\end{array}$ & $0.00-0.31$ & $0.00-0.31$ & $0.00-0.31$ & $\begin{array}{l}\text { Non- } \\
\text { linear }\end{array}$ & $\begin{array}{l}\text { County roads above a } \\
\text { threshold deter carnivores } \\
\text { due to human } \\
\text { presence/traffic. } \\
\text { Predictability of traffic could } \\
\text { result in non-linear effects } \\
\text { for some carnivores that } \\
\text { adapt to heavily roaded areas }\end{array}$ & $\begin{array}{l}\text { Niedziałkowska et al., 2006; Northrup et } \\
\text { al., 2012; Zimmermann et al., } 2014\end{array}$ \\
\hline Communal roads & comrdXmn & $\begin{array}{l}\mathrm{km} / \mathrm{km}^{2} \\
\text { (density) }\end{array}$ & $0.02-0.73$ & $0.02-0.72$ & $0.02-0.72$ & $\begin{array}{l}\text { Non- } \\
\text { linear }\end{array}$ & $\begin{array}{l}\text { Communal roads above a } \\
\text { threshold might deter } \\
\text { carnivores due to } \\
\text { unpredictable traffic, but } \\
\text { carnivores might use roaded } \\
\text { areas due to ease of } \\
\text { movement along roads and } \\
\text { edge effects associated with } \\
\text { high plant and ungulate } \\
\text { productivity }\end{array}$ & $\begin{array}{l}\text { Niedziałkowska et al., 2006; Northrup et } \\
\text { al., 2012; Zimmermann et al., } 2014\end{array}$ \\
\hline
\end{tabular}

1 Code - variable codes used in the modelling script have carnivore species-specific suffixes ("Xmn" in code is replaced with "bmn" - bear; "wmn" - wolf; "lmn" $2-\operatorname{lynx})$ 


\section{Table 2 (on next page)}

Top occurrence models for brown bear, gray wolf and Eurasian lynx.

Variable codes listed under 'Model description' are provided in Table 1. 


\begin{tabular}{|c|c|c|c|c|c|c|c|c|}
\hline Species & Model description & $\mathbf{K}$ & AIC & $\Delta \mathrm{AIC}$ & $w_{i}$ & Dev. & $\begin{array}{l}\% \\
\text { Expl. }\end{array}$ & Dev. \\
\hline Bear & $\begin{array}{l}\text { SDmixedbmn+SDconifbmn+SDn } \\
\text { atrdbmn+SDnatrdbmn²+SDcourd } \\
\text { bmn+SDcourdbmn }{ }^{2}+\text { SDcomrdbm } \\
\text { n+SDcomrdbmn²+SDpastbmn+S } \\
\text { Dpastbmn }{ }^{2}+\text { SDagricbmn+SDagri } \\
\text { cbmn }{ }^{2}+\text { SDartifbmn }\end{array}$ & 14 & 901.08 & 0.0 & 1.00 & 873.1 & 62.7 & \\
\hline Wolf & $\begin{array}{l}\text { SDbrdlfwmn+SDconifwmn+SDn } \\
\text { atrdwmn+SDnatrdwmn²+SDcour } \\
\text { dwmn+SDcourdwmn²+SDcomrd } \\
\text { wmn+SDcomrdwmn }{ }^{2}+\text { SDpastwm } \\
\text { n+SDpastwmn }{ }^{2}+\text { SDartifwmn+Str } \\
\text { iwmn+SDtriwmn }{ }^{2}\end{array}$ & 14 & 1077.1 & 0.0 & 1.00 & 1049 & 62.4 & \\
\hline Lynx & $\begin{array}{l}\text { SDmixedlmn+SDconiflmn+SDna } \\
\text { trdlmn+SDnatrdlmn²+SDcourdlm } \\
\text { n+SDcourdlmn²+SDcomrdlmn+S } \\
\text { Dcomrdlmn }{ }^{2}+\text { SDpastlmn+SDpast } \\
\text { lmn²+SDagriclmn+SDagriclmn }{ }^{2}+ \\
\text { SDartiflmn }\end{array}$ & 14 & 692.9 & 0.0 & 0.99 & 664.9 & 72.2 & \\
\hline
\end{tabular}

$1 \mathrm{~K}$ - number of parameters; AIC - Akaike's Information Criterion; $\triangle \mathrm{AIC}$ - difference in AIC between a given model

2 and the corresponding null model; $w_{i}$ - Akaike weight; Dev. - Residual Deviance; \% Dev. Expl. - Percentage Deviance

3 Explained 


\section{Table 3(on next page)}

Parameter estimates for top brown bear, gray wolf and Eurasian lynx occurrence models. Variable codes listed under "Variable" are provided in Table 1. Estimates for which $95 \%$ confidence intervals did not overlap zero are given in bold. 


\begin{tabular}{|c|c|c|c|c|c|c|c|c|c|}
\hline & Bear & & & Wolf & & & Lynx & & \\
\hline Variable & $\boldsymbol{\beta}$ & SE & OR & $\boldsymbol{\beta}$ & SE & OR & $\boldsymbol{\beta}$ & SE & OR \\
\hline Intercept & $-3.340 * *$ & 0.269 & 0.04 & -0.448 & 0.480 & 0.64 & $-3.349 * *$ & 0.320 & 0.04 \\
\hline \multicolumn{10}{|c|}{ Habitat (Natural) } \\
\hline \multicolumn{10}{|l|}{ Abiotic } \\
\hline triXmn & & & & $4.146 * *$ & 0.616 & 63.18 & & & \\
\hline triXmn ${ }^{2}$ & & & & $-2.366^{* *}$ & 0.541 & 0.09 & & & \\
\hline \multicolumn{10}{|l|}{ Biotic } \\
\hline brdlfXmn & & & & $0.330 * *$ & 0.155 & 1.39 & & & \\
\hline mixedXmn & $0.819 * *$ & 0.178 & 2.27 & & & & $1.019 * *$ & 0.341 & 2.77 \\
\hline conifXmn & $0.818 * *$ & 0.237 & 2.27 & $3.410 * *$ & 1.564 & 30.26 & 0.446 & 0.470 & 1.56 \\
\hline shrXmn & & & & & & & & & \\
\hline \multicolumn{10}{|c|}{ Habitat (Human) } \\
\hline agricXmn & 0.855 & 0.574 & 2.35 & & & & $-1.840 * *$ & 0.710 & 0.16 \\
\hline agricXmn $^{2}$ & $-3.681 * *$ & 0.747 & 0.03 & & & & -1.376 & 0.883 & 0.25 \\
\hline pastXmn & 0.335 & 0.235 & 1.40 & $0.505^{*}$ & 0.286 & 1.66 & $0.765 * *$ & 0.310 & 2.15 \\
\hline pastXmn ${ }^{2}$ & 0.088 & 0.191 & 1.09 & 0.199 & 0.225 & 1.22 & $-0.664 * *$ & 0.255 & 0.52 \\
\hline artifXmn & $-0.426 * *$ & 0.158 & 0.65 & -0.128 & 0.124 & 0.88 & -0.171 & 0.154 & 0.84 \\
\hline natrdXmn & $-0.865^{*}$ & 0.476 & 0.42 & 0.157 & 0.341 & 1.17 & 0.022 & 0.571 & 1.02 \\
\hline natrdXmn ${ }^{2}$ & 0.798 & 0.536 & 2.22 & -0.050 & 0.336 & 0.95 & -0.163 & 0.646 & 0.85 \\
\hline courdXmn & -0.549 & 0.513 & 0.58 & -0.339 & 0.612 & 0.71 & -0.353 & 0.773 & 0.70 \\
\hline courdXmn ${ }^{2}$ & 0.371 & 0.537 & 1.45 & 0.146 & 0.531 & 1.16 & -0.605 & 0.768 & 0.55 \\
\hline comrdXmn & $1.658 * *$ & 0.528 & 5.25 & 0.359 & 0.590 & 1.43 & $3.189 * *$ & 0.717 & 24.27 \\
\hline comrdXmn ${ }^{2}$ & $-2.013 * *$ & 0.501 & 0.13 & -0.782 & 0.536 & 0.46 & $-3.045^{* *}$ & 0.721 & 0.05 \\
\hline
\end{tabular}

$1 \beta$-parameter estimate; SE - Standard error; OR - Odds Ratio; ** - 95\% Confidence intervals do not overlap zero; *

$2-90 \%$ Confidence intervals do not overlap zero 


\section{Figure 1}

A. Brown bear presence (1) and absence (0) based on footprint tracking in 2011 at the level of Romania's WMUs. B. Predicted relative probabilities of brown bear occurrence based on top habitat model.

A. Original density data mapped in Jurj and lonescu (2011) were digitized and converted to 1/0.

B. Predictions refer to potential habitat, not to actual bear presence. Black ellipses provide case examples of areas where conservation efforts could focus to improve habitat suitability and establish/maintain ecological connectivity for brown bear. 


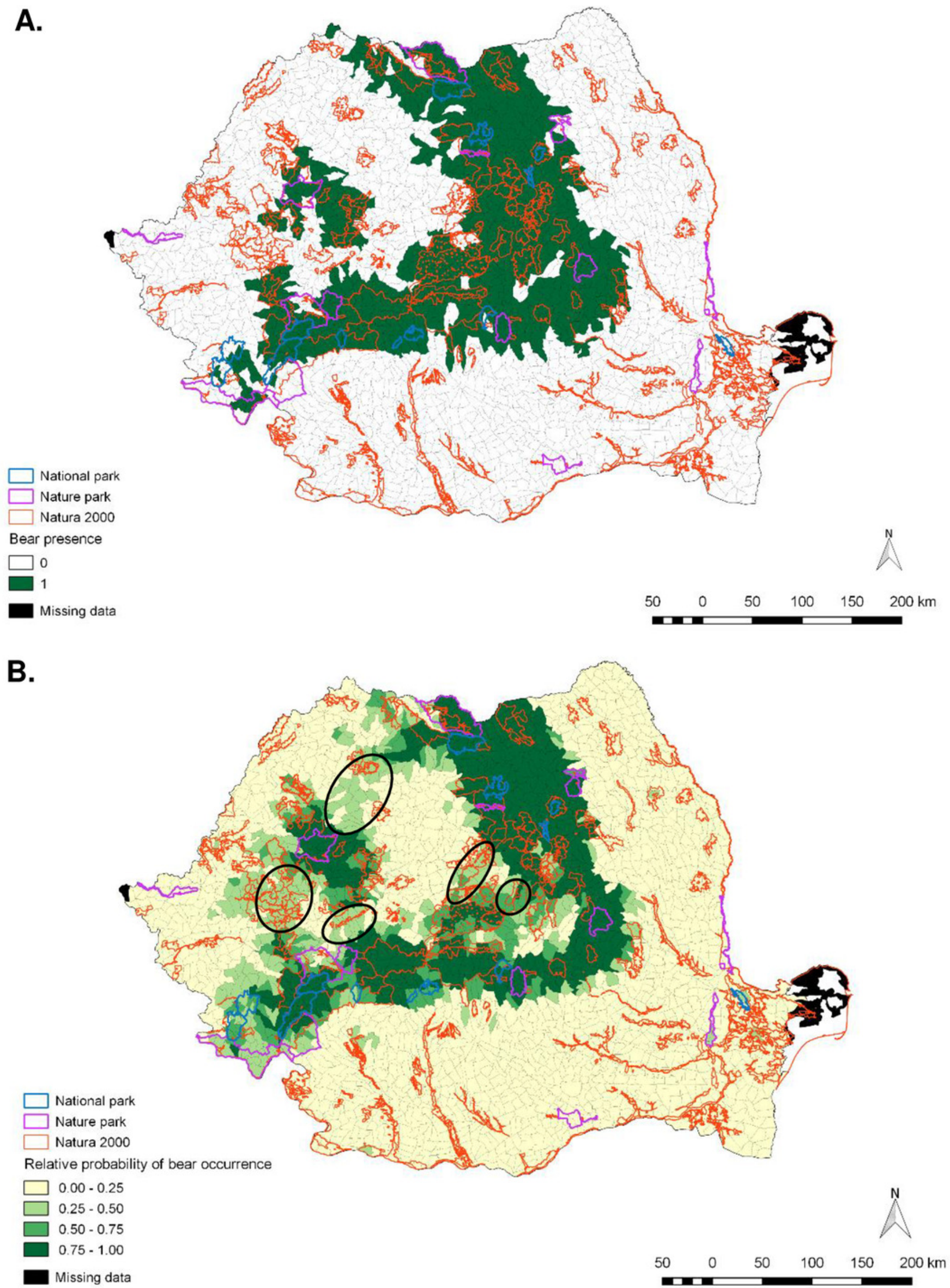




\section{Figure 2}

A. Gray wolf presence (1) and absence (0) based on footprint tracking in 2011 at the level of Romania's WMUs. B. Predicted relative probabilities of gray wolf occurrence based on top habitat model.

A. Original density data mapped in Jurj and lonescu (2011) were digitized and converted to 1/0.

B. Predictions refer to potential habitat, not to actual wolf presence. Black ellipses provide case examples of areas where conservation efforts could focus to improve habitat suitability and establish/maintain ecological connectivity for gray wolf. 
A.

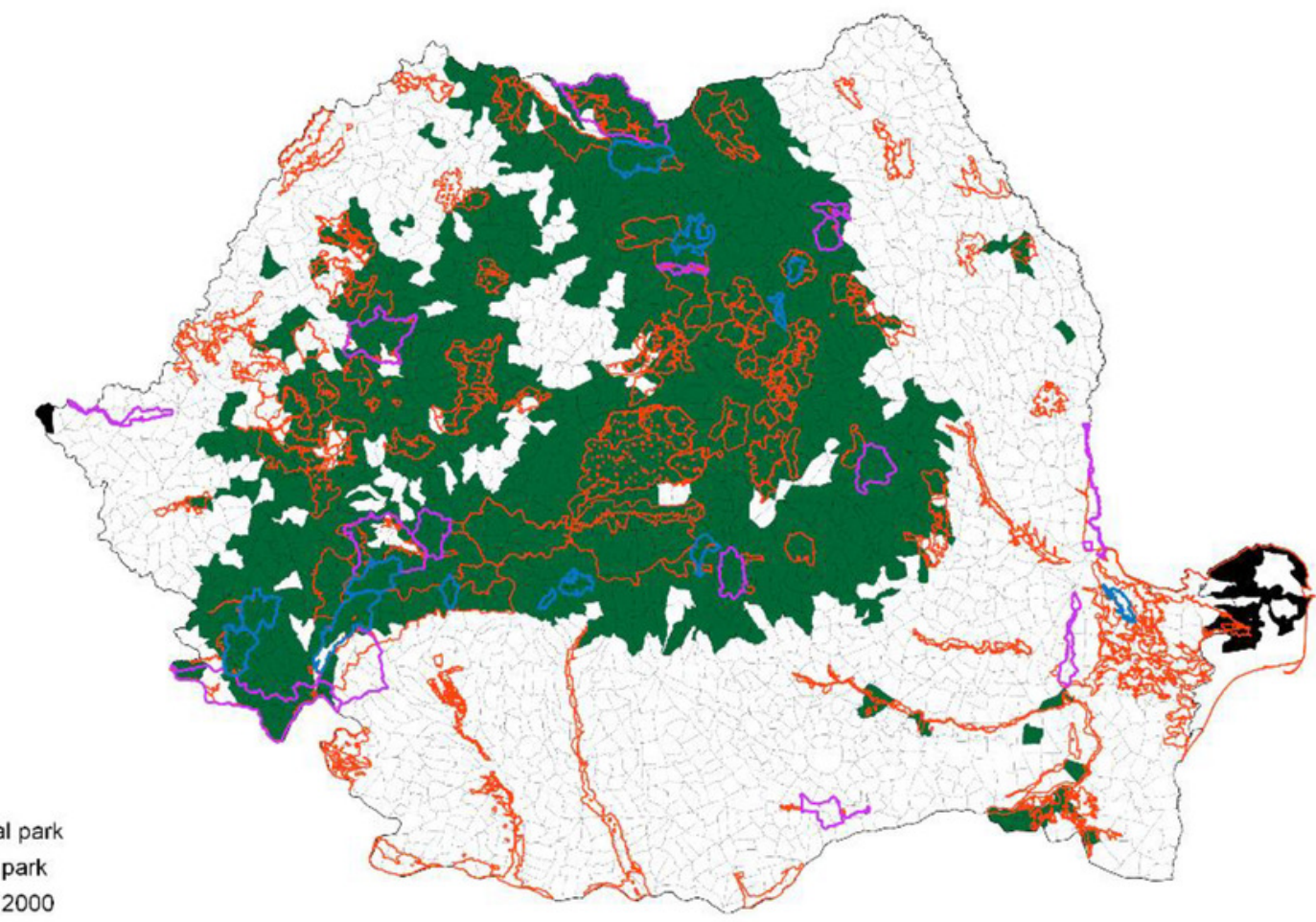

$\square$ National park

Nature park

Jatura 2000

Wolf presence

$\square 0$
$\square 1$

Missing data
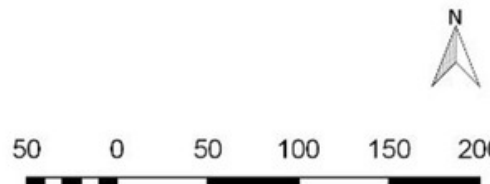

B.

National park

Nature park

Natura 2000

Relative probability of wolf occurrence
$\square 0.00-0.25$
$0.25-0.50$
$0.50-0.75$
$0.75-1.00$
Missing data
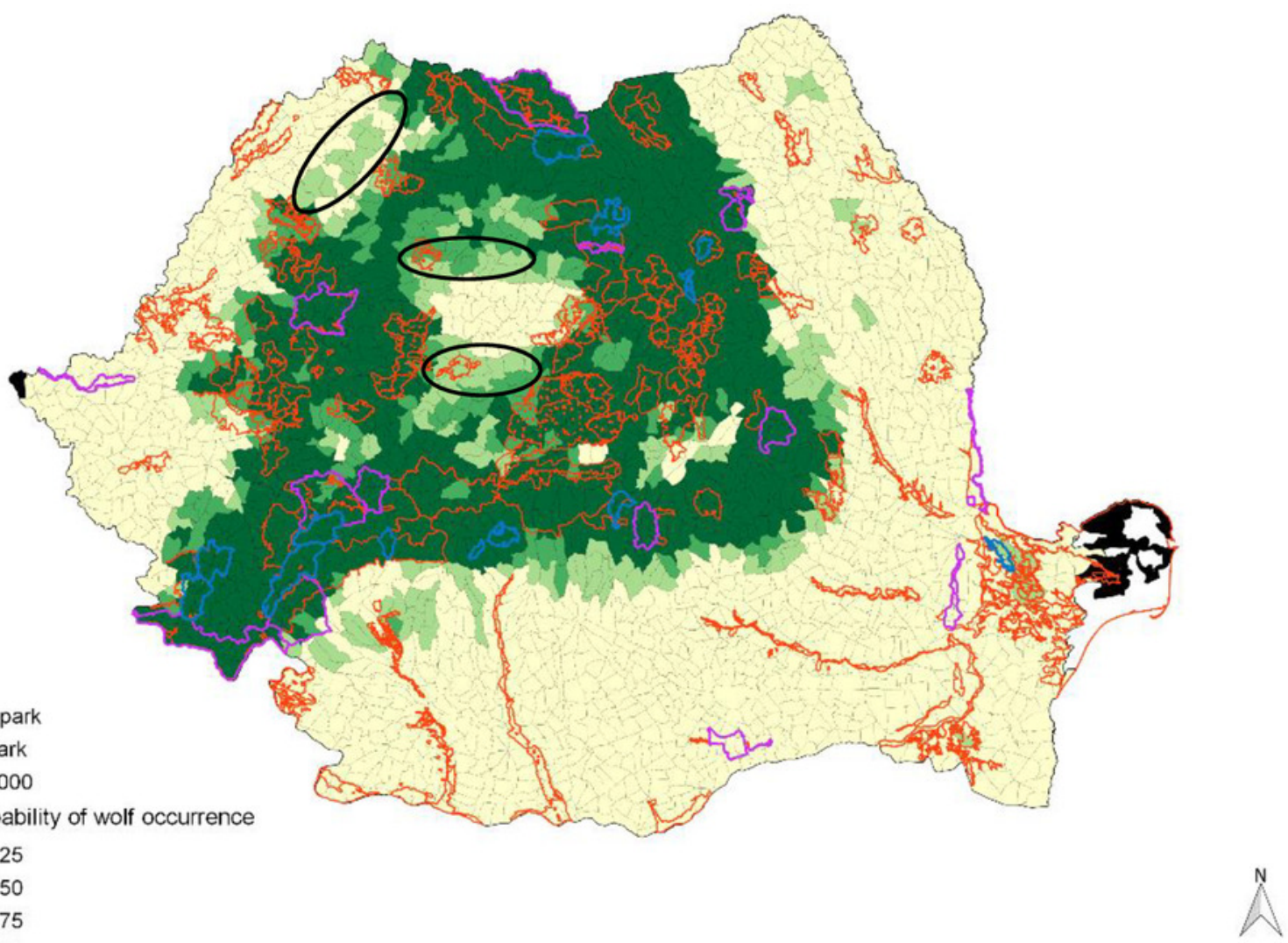

50

\begin{tabular}{rrrrr}
0 & 50 & 100 & 150 & 200 \\
\hline
\end{tabular} 


\section{Figure 3}

A. Eurasian lynx presence (1) and absence (0) based on footprint tracking in 2011 at the level of Romania's WMUs. B. Predicted relative probabilities of Eurasian lynx occurrence based on our top habitat model.

A. Original density data mapped in Jurj and lonescu (2011) were digitized and converted to 1/0.

B. Predictions refer to potential habitat, not to actual lynx presence. Black ellipses provide case examples of areas where conservation efforts could focus to improve habitat suitability and establish/maintain ecological connectivity for Eurasian lynx. 
A.

National park

Nature park

Natura 2000

Lynx presence

$\square$
$\square$
$\square$
$\square$ Missi

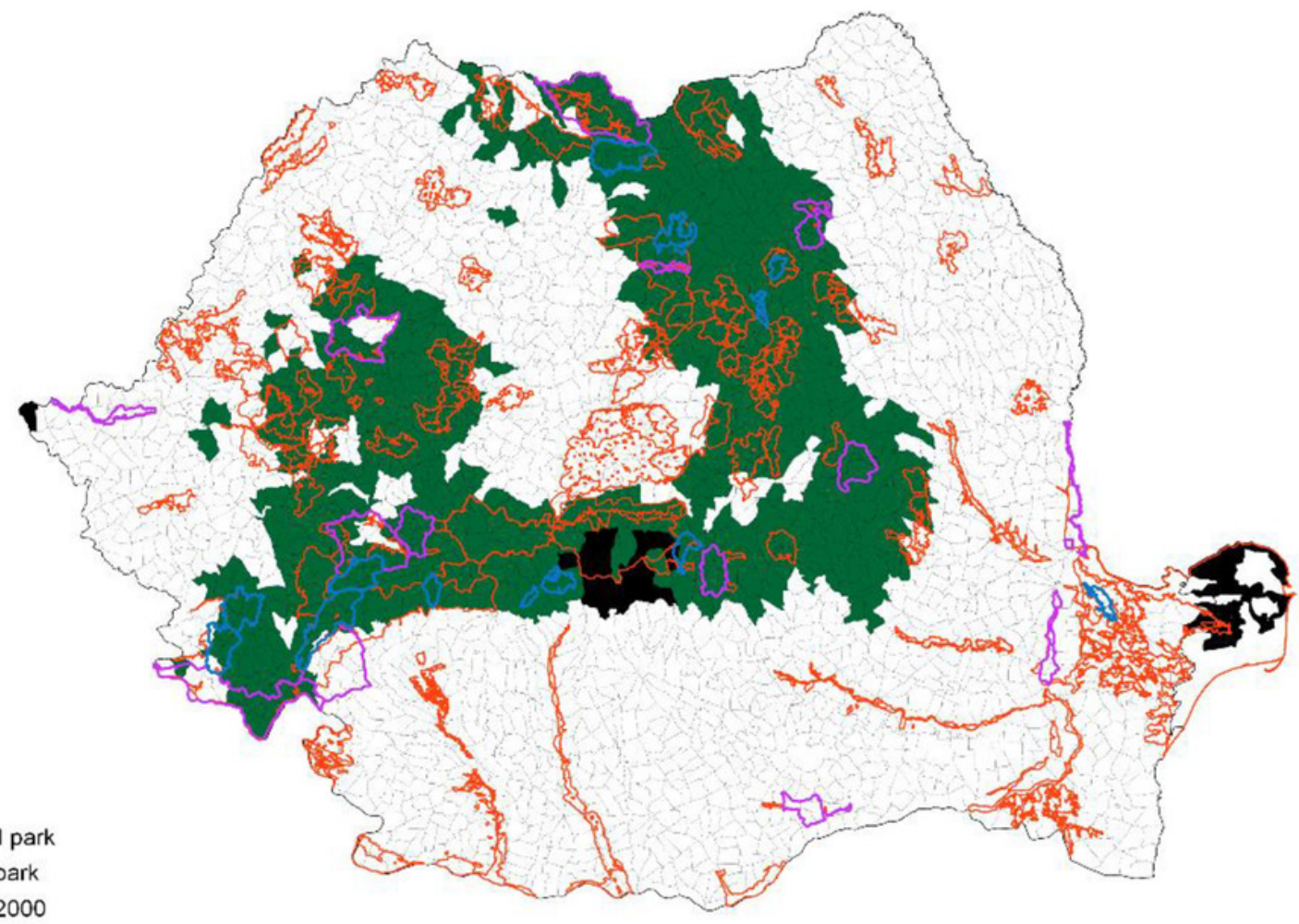

Missing data

50

0

50

B.

National park

Nature park

Natura 2000

Relative probability of lynx occurrence

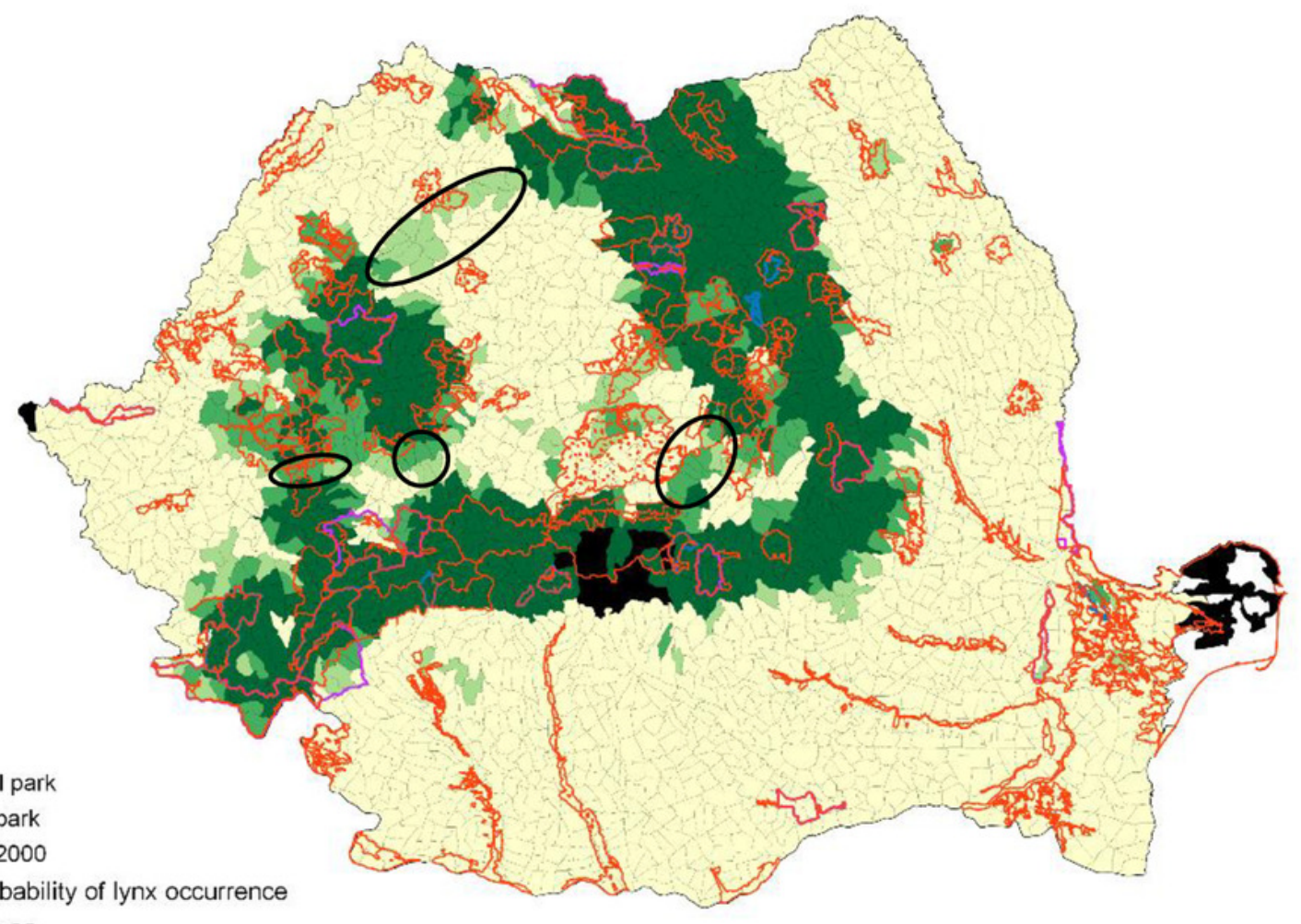

$0.50-0.75$

$0.75-1.00$

Peer reviewing PDF | (2017:10:21462:2:1:NEW 18 Jan 2019)
Missing data

50

0

50 
Figure 4

Predicted relative probabilities of brown bear (A-H), gray wolf (I-P) and Eurasian lynx (Q$\mathrm{X}$ ) occurrence in Romania as a function of predictor variables.

Relationships wherein confidence intervals did not overlap zero have two asterisks (95\%) or one asterisk (90\%).
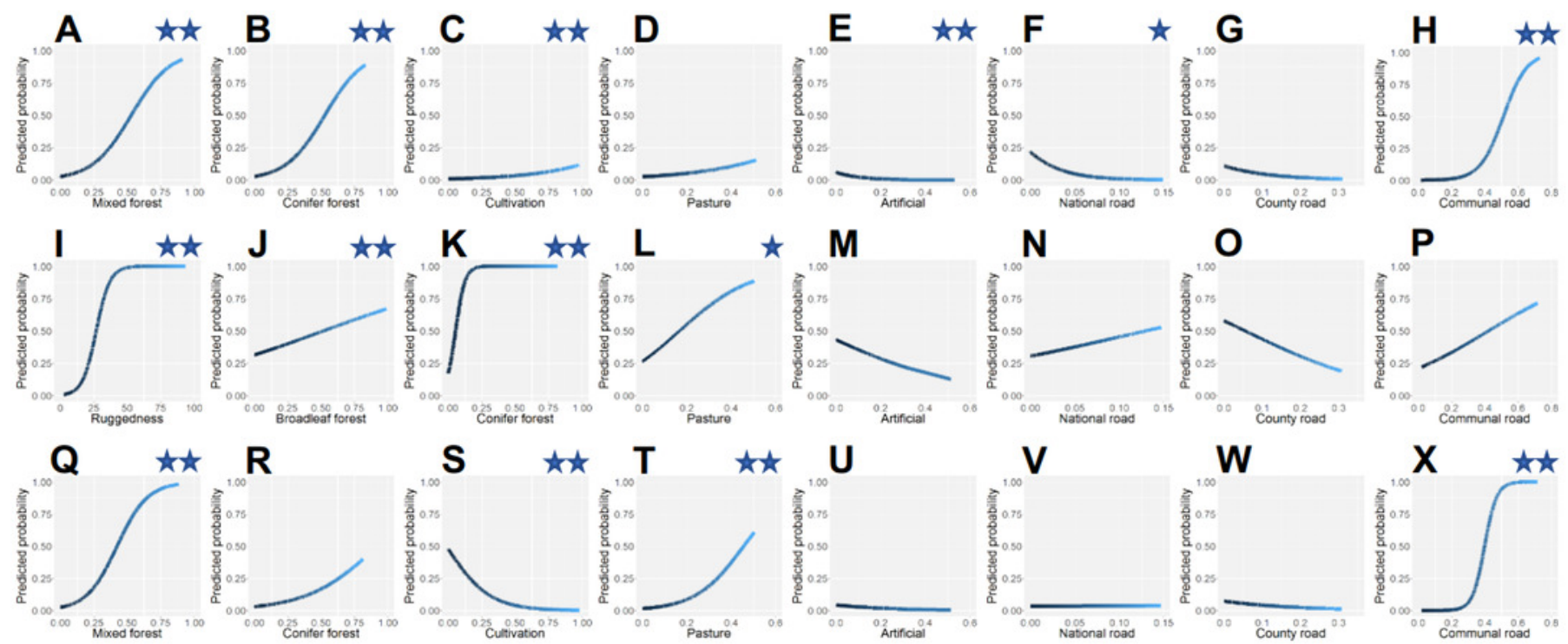
Figure 5

Predicted mean relative probability of occurrence of large carnivores in Romanian national parks (dark green bars), nature parks (medium green) and Natura 2000 sites (light green).

Predictions are given for A. Brown bear; B. Gray wolf; and C. Eurasian lynx. Error bars represent \pm SD.
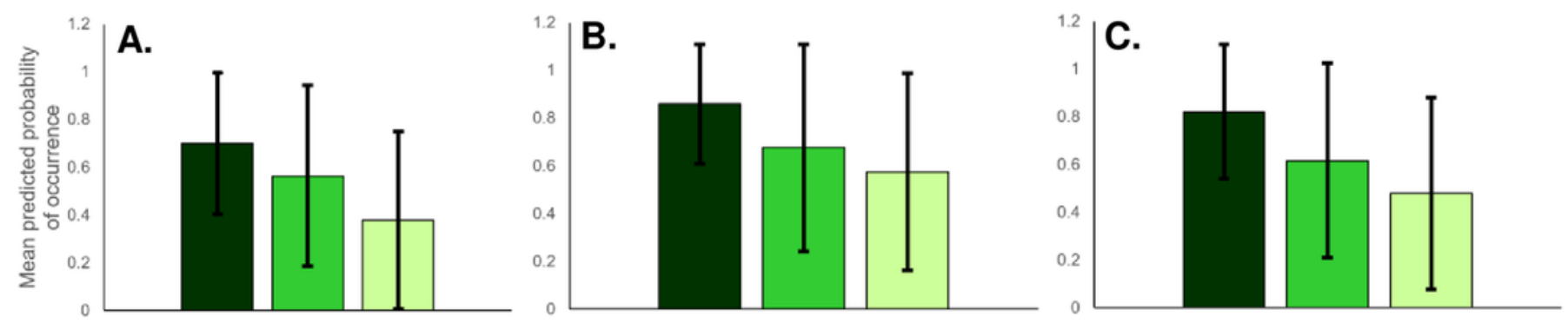